\title{
Bio-organic Nanoparticles: Breaking the Barrier in Nanoparticle-mediated Pulmonary Drug delivery
}

\author{
Arghya Bandyopadhyay ${ }^{1}$ and Subhabrata Moitra2* \\ ${ }^{1}$ Department of Chemical Sciences, Indian Institute of Science Education and Research, India \\ ${ }^{2}$ Department of Pneumology, Allergy \& Asthma Research Centre, India
}

Submission: March 20, 2017; Published: May 08, 2017

*Corresponding author: Dr. Subhabrata Moitra, Department of Pneumology, Allergy \& Asthma Research Centre, Kolkata, India,

Email: subhabrata2207@gmail.com

Keywords: Nanoparticles; Drug delivery; Respiratory medicine; Airway diseases

\section{Introduction}

Nanoparticles (NPs) are emerging as potentially effective targeted drug delivery systems because of their non-invasive approach and lesser bioavailability in the systemic circulation. This specific approach also reduces the potential adverse effects in compared to the drugs administered through oral or invasive routes. NPs also provide an efficient way to selectively deliver ultra-small drugs molecules to the lungs for a better absorption. However, delivering nanoparticles-mediated drugs to the lungs is quite challenging. In lung diseases such as asthma, chronic obstructive pulmonary disease (COPD) or fibrosis, the airways produce excessive amount of mucus as a result of goblet cell hyperplasia and sustained level of severe inflammatory reactions [1].

Controlling inflammation in these persistent inflammatory conditions is the primary target of a successful treatment, however in spite of recent advancement of nanoparticles-based drug delivery systems in various disease conditions; very few have been tested in respiratory illnesses [2-4]. Moreover, the potential toxicity of inorganic nanoparticles is a major concern, therefore it is important to formulate a career molecule which is biodegradable and does not have any potential toxic effects. Solid lipid nanoparticles (SLNs) are being tested as one of the most effective ways of pulmonary drug delivery. SLNs are aqueous nanoscale molecules prepared from phospholipid compounds mainly triglycerides and phospholipids with a potential physiological acceptability [5-7]. Along with SLNs, lipophilic drug delivery through biodegradable polymeric nanoparticles is being tested for their solubility in lipid matrices which could provide an effective therapeutic advantage. Because of the physiological components used in the formulations of the SLNs, they provide a better and safe delivery of drugs to the lungs and since its first application long back in the early 90s, SLNs have been tested as a carrier of a large number of drug molecules such as amikacin, an aminoglycoside antibiotic and have been proved to deliver the drugs effectively to the lungs in the treatment of lung infections [8].

The challenge of pulmonary drugdeliverymightbeachieved by nanoparticulated formulations such as biodegradable polymeric nanoparticles, nanoformulations of drug, and dendrimers. Their relatively higher adsorption rate, biodegradable and almost nontoxic nature provide significant advantages to them as therapeutic choice in compared with other types of materials such as metallic or carbon nanomaterials. Recently, a number of polymeric materials are being investigated for pulmonary drug delivery because of their several advantages such as modified surface properties, high encapsulation of the drug and protection of the drug from degradation, prolonged drug delivery and a long shelf life. The most commonly used polymers which are gaining attention as therapeutics are poly(lactic acid) (PLA), poly(lacticco-glycolic acid) (PLGA), poly( $\varepsilon$-caprolactone) (PCL), alginate, chitosan and gelatin base.

Recently, a combination of polyethylene glycol (PEG5000) and polymer poly(ethylene oxide)-block-distearoyl phosphatidylethanolamine (DSPE) was used to prepare a paclitaxel-loaded polymeric micelle and an in vivo models using intratracheal instillation demonstrated a better drug absorption in comparison with the intravenous route of administration [9]. Liposomes have also been a preferable mode of pulmonary drug 
delivery because of its primary component, phospholipid. One key advantage of liposomes is that these molecules can be used for drugs which require a sustained release that means a precise and controlled release of the drug molecules over a long period of time for a maximum effect. The first liposome-coupled drug was produced 20 years back. Alveofact $\AA$, the first generation product of liposome-drug combination was used to treat acute respiratory distress syndrome (ARDS) in infants by pulmonary instillation [10].

Although liposomes have always been a preferred choice for pulmonary drug delivery, maintaining the physical properties of the liposomes in inhalation devices is a great challenge and therefore it is important to stabilize the product. Nanoformulation of drug has also achieved a great importance for pulmonary drug delivery. It is basically a sole entity, which means that the drug itself is converted into nano-size particles and does not require any carrier molecule. Some of these drugs such as dry powder sodium alendronate can be easily delivered through inhalation devices. Dendrimers are getting attention as in these days. These are nano-size synthetic macromolecules with a highly branched structure and globular shape. Dendrimers contain a large number of terminal groups, which allows these molecules to bind with several drugs at the same time and can deliver them with accuracy and precision.

There are several dendrimer-based formulations available, such as anticancer drug fluorouracil attached to the dendrimers with cyclic core and antitumor drugs adriamycin and methotrexate with dendrimers having poly(ethylene glycol) grafts. Precision and targeted drug delivery is rapidly gaining importance now a days and considering the mechanical improvement of formulation and delivery devices, nanoparticles and nanoparticles-mediated drug delivery are at the peak. However, since the characteristics of the engineered nanocarriers or nano formulations are complex and may change in certain solutions or devices, $\mathrm{t}$ is important to focus on the development of appropriate devices to deliver the drugs effectively. Preclinical and animal studies are extremely important at this stage to investigate the efficacy and safety of these formulations before bringing them as regular treatment modality.

\section{References}

1. Sanders N, Rudolph C, Braeckmans K, De Smedt SC, Demeester J (2009) Extracellular barriers in respiratory gene therapy. Adv Drug Deliv Rev 61(2): 115-127.

2. Rytting E, Nguyen J, Wang X, Kissel T (2008) Biodegradable polymeric nanocarriers for pulmonary drug delivery. Expert Opin Drug Deliv 5(6): 629-639.

3. Card JW, Zeldin DC, Bonner JC, Nestmann ER (2008) Pulmonary applications and toxicity of engineered nanoparticles. Am J Physiol Lung Cell Mol Physiol 295(3): L400-L411.

4. Yang W, Peters JI, Williams III RO (2008) Inhaled nanoparticles- a current review. Int J Pharm 356(1-2):239-247.

5. Nassimi M, Schleh C, Lauenstein H, Hussein R, Hoymann H, et al. (2010) A toxicological evaluation of inhaled solid lipid nanoparticles used as a potential drug delivery system for the lung. Eur J Pharm Biopharm 75: 107-116.

6. Nassimi M, Schleh C, Lauenstein HD, Hussein R, Lübbers K, et al. (2009) Low cytotoxicity of solid lipid nanoparticles in in vitro and ex vivo lung models. Inhal Toxicol 21(Suppl 1): 104-109.

7. Paranjpe M, Neuhaus V, Finke JH, Richter C, Gothsch T, et al. (2013) In vitro and ex vivo toxicological testing of sildenafil-loaded solid lipid nanoparticles. Inhal Toxicol 25(9): 536-543.

8. Varshosaz J, Ghaffari S, Mirshojaei SF, Jafarian A, Atyabi F, et al. (2013) Biodistribution of amikacin solid lipid nanoparticles after pulmonary delivery. BioMed Res Int.

9. Gill KK, Nazzal S, Kaddoumi A (2011) Paclitaxel loaded PEG5000DSPE micelles as pulmonary delivery platform: Formulation characterization, tissue distribution, plasma pharmacokinetics, and toxicological evaluation. Eur J Pharm Biopharm 79(2): 276-284.

10. Adler-Moore J, Proffitt RT (2002) AmBisome: Liposomal formulation, structure, mechanism of action and pre-clinical experience. J. Antimicrob Chemother 49(Suppl 1): 21-30.

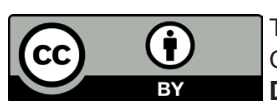

This work is licensed under Creative Commons Attribution 4.0 Licens DOI: 10.19080/IJOPRS.2017.01.555568

\section{Your next submission with Juniper Publishers} will reach you the below assets

- Quality Editorial service

- Swift Peer Review

- Reprints availability

- E-prints Service

- Manuscript Podcast for convenient understanding

- Global attainment for your research

- Manuscript accessibility in different formats

( Pdf, E-pub, Full Text, Audio)

- Unceasing customer service

Track the below URL for one-step submission https://juniperpublishers.com/online-submission.php 